\title{
Comparison of morning and afternoon exercise training for asthmatic children
}

\section{C.S. Silva ${ }^{1}$, \\ L.A.G.M.M. Torres ${ }^{2}$, \\ A. Rahal ${ }^{3}$, \\ J. Terra Filho ${ }^{1}$ and E.O. Vianna ${ }^{1}$}

\author{
'Divisão de Pneumologia, Departamento de Clínica Médica, \\ ${ }^{2}$ Departamento de Pediatria, Faculdade de Medicina de Ribeirão Preto, \\ ${ }^{3}$ Centro de Educação Física e Recreação, Universidade de São Paulo, \\ Ribeirão Preto, SP, Brasil
}

\begin{abstract}
Correspondence

E.O. Vianna

Divisão de Pneumologia

Departamento de Clínica Médica

FMRP, USP

Av. Bandeirantes, 3900

14048-900 Ribeirão Preto, SP

Brasil

Fax: +55-16-3633-6695

E-mail: evianna@uol.com.br

Research supported by FAPESP.

Received April 8, 2005

Accepted September 19, 2005

....................

Fitness improvement was used to compare morning with afternoon exercise periods for asthmatic children. Children with persistent moderate asthma (according to GINA criteria), 8 to 11 years old, were divided into 3 groups: morning training group $(\mathrm{N}=23)$, afternoon training group $(\mathrm{N}=23)$, and non-training group $(\mathrm{N}=23)$. The program was based on twice a week 90 -min sessions for 4 months. We measured the 9-min running distance, resting heart rate and abdominal muscle strength (sit-up number) before and after the training. All children took budesonide, $400 \mu \mathrm{g} / \mathrm{day}$, and an on demand inhaled $\beta$ agonist. The distance covered in 9 min increased (mean \pm SEM) from $1344 \pm 30 \mathrm{~m}$ by $248 \pm 30 \mathrm{~m}$ for the morning group, from $1327 \pm 30 \mathrm{~m}$ by $162 \pm 20 \mathrm{~m}$ for the afternoon group, and from $1310 \pm 20 \mathrm{~m}$ by $2 \pm 20 \mathrm{~m}$ for the control group $(\mathrm{P}<0.05$ for the comparison of morning and afternoon groups with the control group by ANOVA and $\mathrm{P}>0.05$ for morning with afternoon comparison). The reduction of resting heart rate from $83 \pm 1,85 \pm 2$ and $86 \pm 1$ bpm was $5.1 \pm 0.8 \mathrm{bpm}$ in the morning group, $4.4 \pm 0.8 \mathrm{bpm}$ in the afternoon group, and $-0.2 \pm 0.7 \mathrm{bpm}$ in the control group $(\mathrm{P}>0.05$ for morning with afternoon comparison and $\mathrm{P}<0.05$ versus control). The number of situps in the morning, afternoon and control groups increased from 22.0 $\pm 1.7,24.3 \pm 1.4$ and $23 \pm 1.1$ sit-ups by $9.8 \pm 0.9,7.7 \pm 1.4$, and $1.9 \pm 0.7$ sit-ups, respectively $(\mathrm{P}>0.05$ for morning with afternoon comparison and $\mathrm{P}<0.05$ versus control). No statistically significant differences were detected between the morning and afternoon groups in terms of physical training of asthmatic children.
\end{abstract}

Key words

- Asthma

- Children

- Chronotherapy

- Exercise training

- Circadian rhythm

- Exercise-induced

bronchospasm

\section{Introduction}

Circadian rhythms or diurnal variations in responses to exercise have been studied in recent years (1-5). Results have depended on a variety of factors in the experimental design, such as kind and intensity of exer- cise, and other parameters. It is clear, however, that there are some differences in response to exercise that depend on the time of day when the activity is performed (5). The importance of exercise for health is well known; however, there are no prescribed guidelines about the relative effects of exer- 
cising at different times of day. These may be important for both the safety and efficacy of training programs.

More and more, physical exercise is commonly suggested and indicated for children with chronic disease. Asthma patients frequently have poor fitness that can lead to social isolation, further increasing the negative self-concept (6-8). Although regular physical exercise cannot cure asthma, several studies have suggested that physical exercise is an essential component of pulmonary rehabilitation (9). For asthmatic children, physical training increases exercise tolerance, improves fitness, flexibility, muscle strength, decreases use of medication, decreases school absenteeism, and improves self-esteem and confidence $(9,10)$. Different exercise programs have been evaluated mainly regarding duration, frequency and modalities, for example, comparing activities that induce a minimum of exerciseinduced bronchospasm (EIB) (10). At present, it is not known whether time of day influences the effects of a set training regimen for asthmatic sedentary children.

Nocturnal worsening of asthma is a recognized and important aspect of the disorder and must be considered in the management of the disease process. For the diurnally active asthmatic patient, a circadian pattern in lung function (for example, $\mathrm{FEV}_{1}$ ) occurs, the lung function peak occurring at approximately 16:00 $\mathrm{h}$ and the nadir at approximately 4:00 $\mathrm{h}$ $(11,12)$. Based on the characteristics of asthma, that oscillate according to a circadian rhythm, we hypothesized that time of day may influence the effects of physical exercise training. Therefore, we designed this study to compare morning with afternoon exercise by asthmatic children in an exercise training program.

\section{Subjects and Methods}

\section{Subjects}

Sixty-nine children with persistent mod- erate asthma, 8-11 years of age, were enrolled in this prospective trial. The children were randomly assigned to 3 groups of 23 subjects each: morning training group (morning), afternoon training group (afternoon), and non-training group (control). Although the children were physically active, none was following a regular exercise training program. The children were in a stable phase of the disease, with no exacerbation during the 15 days before the beginning of the tests.

The inclusion criteria were physiciandiagnosed asthma classified according to the Global Initiative for Asthma (13) and clinical stability in the 6 weeks preceding the tests. Exclusion criteria were use of oral steroids in the previous 8 weeks, physical disability, and other pulmonary or systemic disease.

All children included in the study were taking budesonide, $400 \mu \mathrm{g} /$ day, and an inhaled B-agonist (albuterol) as needed for at least 1 month before evaluation for the study. None were taking oral steroids, theophylline, a long-acting $B$-agonist, a leukotriene modifier, or cromone. All medication was offered and the prescription was not modified during the study period. Medical follow-up was performed by the same staff physician.

The study was approved by the Institutional Ethics Committee of the University of São Paulo Medical School at Ribeirão Preto. Written informed consent was obtained from the children and their parents. Patient transportation (home to study site, round trip) was provided by the investigators.

\section{Protocol}

A clinical history was obtained from all subjects, followed by physical examination, anthropometry and $\mathrm{FEV}_{1}$ measurement. On a different day, patients performed an exercise challenge test after measurement of resting heart rate. One day before the initial sessions of exercise training, number of sit- 
ups in $60 \mathrm{~s}$ and 9-min running distance were evaluated for the three groups. The subjects of all three groups were evaluated before and after a 4-month period of training.

The physical training program was based on twice weekly 90-min sessions over a period of 4 months (from November to February). The morning group was assigned to sessions starting at 9:00 $\mathrm{h}$ and the afternoon group to sessions starting at 14:30 h. All patients attended at least $80 \%$ of the exercise sessions and their clinical course was stable during this 4-month period.

The children and their parents were submitted to an educational program at the time of diagnosis, i.e., before the training program. Our approaches were: teaching asthma self-management, basic facts about asthma, role of medication, environmental control measures, and skills (inhaler use and selfmonitoring).

\section{Exercise training program}

A physical educator and a physiotherapist were present during all training sessions. The sessions were performed twice a week for a total of 32 sessions. An inhaled Bagonist (albuterol) was administered $10 \mathrm{~min}$ before training. The program was designed to provide aerobic fitness, to improve the compliance of the asthmatic subjects, and to avoid triggering of EIB. Thus, during the first 5 min, no running was allowed. During circuit training, children worked hard for short periods of time during each phase. The results were noted and compared with previous results for the same child.

The tasks were walking for $5 \mathrm{~min}$ and running for 10-15 min (progressively increased during the program). Patients performed upper and lower limb exercises (skipping rope, body lifting movements, stepping on a bench), abdominal muscular strengthening (sit-ups), training on a bar, individual and team games, and postural exercise. Flexibility and stretching exercises (warm-up and cool-down) were taught and performed during the sessions (total time on dry land, $45 \mathrm{~min}$ ).

The supervised exercise in the outdoor swimming pool (water temperature of $29^{\circ} \mathrm{C}$ ) consisted of adaptation to water based on recreational games and natural movements in the water. The next step was control of respiration, initiated by immersing the face in water. Children were encouraged to immerse their faces in water slowly, briefly and progressively longer. Then, they proceeded to respiratory exercises: frontal, lateral and bilateral respiration. To perform flotation exercises, all children were encouraged to float by lying face up and face down in the water with the aid of boards and other accessories. Propulsion and diving were also taught. Learning of swimming styles was initiated with crawl and backstroke (total time in the swimming pool, $45 \mathrm{~min}$ ).

\section{Baseline and post-training evaluations}

Anthropometric and spirometric evaluation. Children were measured for body height in the standing position and for weight wearing light clothes and no shoes. Spirometric tests were done with a Koko spirometer and software (PDS Instrumentation, Inc., Louisville, CO, USA). Patients were asked to refrain from the short-acting bronchodilator for at least $12 \mathrm{~h}$ before testing. Technical procedures, acceptability and reproducibility criteria were those recommended by the American Thoracic Society (14).

Resting heart rate. To ensure that heart rate would not be altered by medication, subjects withheld all medication for $12 \mathrm{~h}$ before assessment. Moreover, the interval between the last dose of the bronchodilator and heart rate assessment was the same before the baseline and post-training assessments. The children rested for $10 \mathrm{~min}$ and the palpation method at the wrist (radial artery) was used to count for $1 \mathrm{~min}$ or more $(15,16)$. 
Evaluation of exercise-induced bronchospasm. Although EIB was not a study outcome, tests were done to characterize our sample on a separate day from the assessment of number of sit-ups in $60 \mathrm{~s}$ and 9-min running distance. Exercise challenge tests were performed on a treadmill using a 6-min challenge protocol as described previously $(12,17)$. Briefly, after $1 \mathrm{~min}$ of light exercise on the inclined $\left(10^{\circ}\right)$ treadmill, the speed was quickly increased to achieve a heart rate corresponding to $80 \%$ of the maximum predicted heart rate (220 - age); this speed was then maintained for $6 \mathrm{~min}$. Standard spirometry measurements were performed before, immediately after, and 5, 10, 15, 20, 30, and $45 \mathrm{~min}$ after exercise.

Abdominal muscle strength. Abdominal strength was measured by the number of situps completed in $60 \mathrm{~s}$. The children lay down on a gym mat with knees flexed and feet 12 inches from the buttocks. The feet were not held or anchored. Arms were extended forward with the fingers resting on the legs and pointing toward the knees. Another child served as the counter by kneeling near the feet of the participant and placing his hands at the base of the patella of each leg. The children being tested curled up slowly sliding their fingers up the legs until they touched the fingers of the person counting the repetitions. After making contact, the person being tested slowly moved back down until his shoulder blades come in contact with the mat. After a 1-min time limit, the total number of complete repetitions was recorded. The movement was continuous, with no rest allowed. The children were instructed to do the curl-ups slowly, with their knees bent and their feet not held (18).

Nine-minute running distance. Cardiovascular fitness was measured by the distance covered in a 9-min run. The bronchodilator was administered 20 min before the exercise to reduce the possibility that EIB would limit performance in the test. All testing sessions took place at the same time of day under the same conditions and were administered by two examiners. Heart rate was assessed during the test with a Polar HR monitor (Polar Beat, Polar Electro Inc., Kempele, Finland). The effort was not considered valid unless the patient had a heart rate of at least $75 \%$ of the maximum predicted heart rate (220 - age) at the end of the running period (19).

\section{Statistical analysis}

Data are reported as means \pm SEM. The normality of data distribution was determined by the Kolmogorov-Smirnov test. The intra-group (initial to final) and betweengroup comparisons were made by ANOVA followed by the Tukey-Kramer multiple comparisons test. The primary outcome was considered to be fitness, i.e., the increase in running distance and decrease in heart rate. Power calculation: a sample size of 23 had $90 \%$ power to detect a difference of $150 \mathrm{~m}$ in increases in the 9-min run distance. The statistical computer software GraphPad Instat (version 3.05) and JMP (version 3.1) were used for analysis. Values of $\mathrm{P}<0.05$ were considered to be significant.

\section{Results}

In the initial evaluation, the three groups did not differ with respect to age, height, weight, $\mathrm{FEV}_{1}$, or EIB. The characteristics of the groups are shown in Table 1. From the initial to the final measurements, changes in $\mathrm{FEV}_{1}$ were not significant. Values of $\mathrm{FEV}_{1}$ (mean $\pm \mathrm{SEM}$ ) before and after the exercise program were $1.68 \pm 0.07$ and $1.76 \pm 0.07 \mathrm{~L}$, respectively, for the control group. Values were $1.73 \pm 0.06$ and $1.81 \pm 0.05 \mathrm{~L}$ for the morning group and $1.74 \pm 0.08$ and $1.80 \pm$ $0.07 \mathrm{~L}$ for the afternoon group. $\mathrm{FEV}_{1}$ reported as percent of the predicted value also showed no significant difference $(\mathrm{P}>0.05$ for the following comparisons): for the control group, $\mathrm{FEV}_{1}$ was $87 \pm 3$ (initial) and 
$85 \pm 3 \%$ (final); for the morning group, $85 \pm 3$ (initial) and $86 \pm 2 \%$ (final), and, for the afternoon group, $87 \pm 3$ (initial) and $88 \pm 3 \%$ (final).

\section{Nine-minute running distance}

Results of the distance covered in the 9min run showed a significant increase in the morning group $(1344 \pm 30$ to $1592 \pm 40 \mathrm{~m}, \mathrm{P}$ $<0.001)$ and in the afternoon group $(1327 \pm$ 30 to $1489 \pm 30 \mathrm{~m}, \mathrm{P}<0.05)$. The distance did not change in the control group (1310 \pm 20 to $1313 \pm 30 \mathrm{~m}, \mathrm{P}>0.05$; Figure 1 ).

Table 2 displays the changes in 9-min running distance for all groups. These changes were different between the training groups and the control group. The control group did not improve significantly. The 9min running distance increase did not differ between the morning and the afternoon groups.

\section{Resting heart rate}

The value of resting heart rate was $83 \pm 1$ (initial) and $78 \pm 2 \mathrm{bpm}$ (final) in the morning group, and $85 \pm 2$ (initial) and $80 \pm 1 \mathrm{bpm}$ (final) in the afternoon group (significantly different for both groups). In the control group, resting heart rate was $86 \pm 1$ before and $86 \pm$ $1 \mathrm{bpm}$ after the study period $(\mathrm{P}>0.05)$.

The values of the differences (final minus initial) are shown in Table 2. The heart rate reduction was similar for the training groups and significantly greater compared to control.

\section{Abdominal muscle strength}

The number of sit-ups increased for the morning group $(22.0 \pm 1.7$ to $32.0 \pm 1.8$ situps, $\mathrm{P}<0.001$ ) and for the afternoon group $(24.3 \pm 1.4$ to $32.1 \pm 1.4$ sit-ups, $\mathrm{P}<0.01)$. Sit-up number did not significantly change for the control group ( $23 \pm 1.1$ to $25 \pm 1.2$ situps, $\mathrm{P}>0.05$ ).
Table 1. Anthropometric and pulmonary function data of the asthmatic patients studied.

\begin{tabular}{lccc}
\hline & Control group & Morning group & Afternoon group \\
\hline Age (years) & $9.5 \pm 0.2$ & $9.5 \pm 0.2$ & $9.2 \pm 0.2$ \\
Male/female & $11 / 12$ & $12 / 11$ & $12 / 11$ \\
Weight $(\mathrm{kg})$ & $32.1 \pm 1.8$ & $36.6 \pm 2.0$ & $32.4 \pm 1.7$ \\
Height $(\mathrm{cm})_{\text {FEV }}(\mathrm{L})$ & $134 \pm 1$ & $138 \pm 1$ & $136 \pm 1$ \\
FEV $_{1}(\%)$ & $1.68 \pm 0.07$ & $1.73 \pm 0.06$ & $1.74 \pm 0.08$ \\
EIB $(\mathrm{L})$ & $87 \pm 3$ & $85 \pm 3$ & $87 \pm 3$ \\
EIB $(\%)$ & $0.30 \pm 0.04$ & $0.37 \pm 0.06$ & $0.36 \pm 0.04$ \\
& $21.3 \pm 19.0$ & $21.8 \pm 17.3$ & $22.6 \pm 16.3$
\end{tabular}

Data are reported as means \pm SEM for 23 subjects in each group. EIB $(L)=$ exerciseinduced bronchospasm (maximum fall in $\mathrm{FEV}_{1}$ ); EIB $(\%)=$ exercise-induced bronchospasm reported as percent fall.

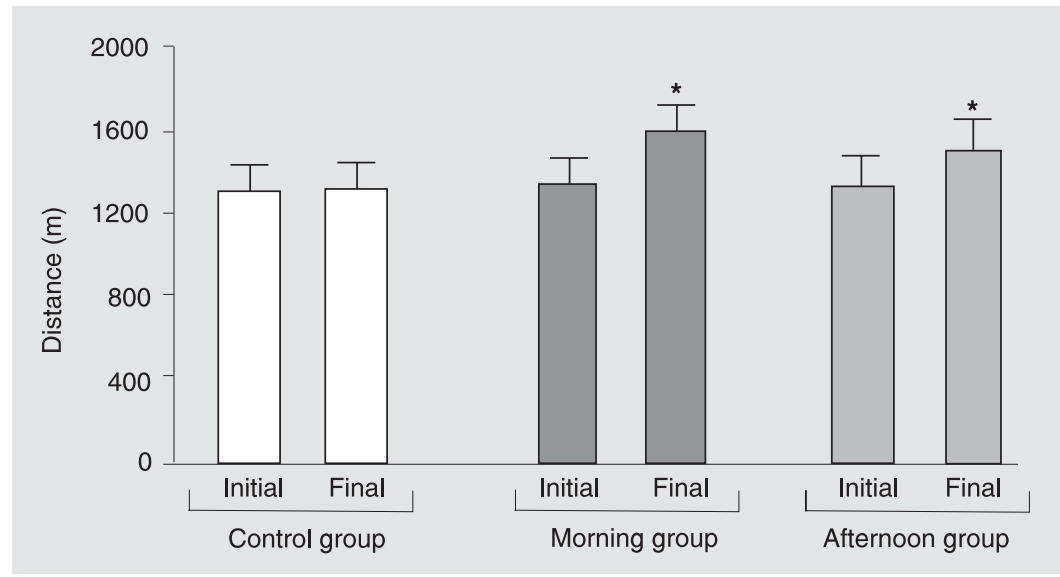

Figure 1. Effect of morning and afternoon exercise on the 9-min run distance covered by asthmatic children. Initial and final indicate the distances run, respectively, before and after a 4-month training program or before and after the same follow-up period for the control group $(\mathrm{N}=23)$. A training program of twice a week 90 -min sessions was performed at 9:00 $\mathrm{h}$ in the morning group $(\mathrm{N}=23)$ and at 14:30 $\mathrm{h}$ in the afternoon group $(\mathrm{N}=23) .{ }^{*} \mathrm{P}<0.05$ compared with initial values and to control. $\mathrm{P}>0.05$ for morning with afternoon final value comparisons (ANOVA).

Table 2. Effect of morning and afternoon exercise by asthmatic children on the results of the exercise program.

\begin{tabular}{lccc}
\hline & Control group & Morning group & Afternoon group \\
\hline Nine-min run $(\mathrm{m})$ & $2 \pm 20$ & $248 \pm 30^{*}$ & $162 \pm 20^{*}$ \\
Resting heart rate (bpm) & $0.2 \pm 0.7$ & $-5.1 \pm 0.8^{*}$ & $-4.4 \pm 0.8^{*}$ \\
Abdominal strength (sit-ups) & $1.9 \pm 0.7$ & $9.8 \pm 0.9^{*}$ & $7.7 \pm 1.4^{*}$ \\
\hline
\end{tabular}

Data are reported as means \pm SEM for 23 subjects in each group, and indicate final minus initial values. The initial values for distance covered in 9 min were $1344 \pm 30$, $1327 \pm 30$ and $1310 \pm 20 \mathrm{~m}$, respectively, for the morning group, afternoon group, and control group ( $P>0.05$ for the comparison of all groups by ANOVA). The values of resting heart rate were $83 \pm 1,85 \pm 2$ and $86 \pm 1 \mathrm{bpm}$, respectively, for the morning group, afternoon group, and control group $(P>0.05)$. The initial values of number of sit-ups in the morning, afternoon and control groups were $22.0 \pm 1.7,24.3 \pm 1.4$ and 23 \pm 1.1 sit-ups, respectively $(P>0.05)$. ${ }^{*} P<0.05$ compared to control and $P>0.05$ for morning with afternoon comparisons (ANOVA). 
The change in sit-up number for each group is shown in Table 2. The increase did not differ between the morning and afternoon groups, with both groups differing from control.

\section{Discussion}

In this study, we compared morning with afternoon physical training for asthmatic children regarding benefits for exercise parameters. The training program was supplementary to regular asthma treatment with medication and education. We detected improvements in running distance, resting heart rate and number of sit-ups in comparison with non-trained children (control group). The improvement of the morning group (training at 9:00 h) was similar to that of the afternoon group (training at 14:30 h). $\mathrm{FEV}_{1}$ values before and after the exercise regimen did not change significantly.

The present data suggest improvement in both fitness and muscle strength. The distance run in 9 min measures the fitness improvement (18-20). Time-based walk/run tests of 9 and 12 min yield reliable measurements and have been shown to correlate closely with the maximal oxygen consumption measured on a treadmill $(19,20)$. Sit-ups are used to measure strength. Adequate strength allows individuals to perform simple tasks effectively and also improves health. Nine-minute running distance and sit-ups are components of the American Alliance of Health, Physical Education, Recreation and Dance Health Related Fitness Test (20).

Another measurement used in the present study to evaluate cardiovascular fitness was resting heart rate. Heart rate has been the variable most commonly analyzed in exercise physiology. Due to its marked sensitivity to any increase or decrease in conditioning, heart rate has become a valuable gauge for the determination of fitness and of compliance with exercise programs. This measurement is of low cost, is well accepted by volunteers and is accurate. Heart rate is an indirect estimate of physical activity, which permits assumptions based on the linear relationship between heart rate and oxygen uptake $(15,16)$.

The present study was not designed to assess modifications in pulmonary function or clinical parameters of asthma. Previous studies have failed to demonstrate improvement in these variables as the result of exercise training $(21,22)$. Nickerson et al. (22) studied the effect of a 6-week training program in 15 children with severe asthma. There was a significant increase in the distance run after the training period, with no difference in the morning peak flow, resting $\mathrm{FEV}_{1}$ or degree of EIB. However, there is some controversy regarding this subject $(23,24)$. Neder et al. (24) allocated children to physical training or to a control group and found that training led to significant reductions in the use of both inhaled and oral steroids. A systematic review was undertaken to gain a better understanding of the effects of physical training on the health of subjects with asthma. The authors concluded that physical training improves cardiopulmonary fitness without changing lung function, although it is not clear if the improvement in fitness translates into a reduction in symptoms or an improvement in the quality of life (9). Thus, there is conflicting evidence on the effects of physical training on lung function, but there is enough evidence to suggest that exercise parameters are more likely to improve after training programs than asthma status, a fact that led us to choose fitness as the primary outcome in our study.

The best time of day to carry out training programs for healthy people has been of interest to some investigators. Torii et al. (5), in a prospective trial comparing morning, afternoon and evening times for exercise over a 4-week period, suggested that aerobic training is most effective in the afternoon. This improvement was detected on the basis 
of heart rate, blood lactate response and maximal oxygen consumption in 4 healthy sedentary men, who constituted the afternoon group. Other studies addressed the effect of time of day on performance by comparing performance at different time points independently of the previous training time. Circadian rhythms may affect athletic performances by variations in thermoregulatory, cardiocirculatory, ventilatory, respiratory, and metabolic responses both at rest and during aerobic exercise (4,25-28). In the present study, we did not address the best time of day to achieve the highest performance. To be conclusive, more studies on the ideal time to exercise for asthma patients are necessary, including studies on diurnal variation in maximal exercise performance.

Training programs are very different in exercise pattern, frequency, duration, and intensity. The benefits of exercise training in children with asthma have been evaluated and discussed by several investigators (610). Exercise training is the main component of pulmonary rehabilitation programs (9). It has been shown to improve aerobic conditioning (15) and abdominal (18) and respiratory muscle strength (28), results that are similar to ours. As a peculiarity of our program, we employed two sessions per week, mixed exercises on dry land and water, including recreational activities to improve patient compliance.

\section{References}

1. Reilly T, Robinson G \& Monors DS (1984). Some circulatory responses to exercise at different times of day. Medicine and Science in Sports and Exercise, 16: 477-482.

2. Wojtczak-Jaroszowa J \& Banaszkiewitcz A (1974). Physical work capacity during the day and night. Ergonomics, 17: 193-198.

3. Hill DW, Cureton KJ, Collins MA et al. (1988). Effect of the circadian rhythm in body temperature on oxygen uptake. Journal of Sports Medicine and Physical Fitness, 28: 310-312.

4. Atkinson $G$ \& Reilly $T$ (1996). Circadian variation in sports performance. Sports Medicine, 21: 292-312.

5. Torii J, Shinkai S \& Hino S (1992). Effect of time of day on adaptive response to a 4-week aerobic exercise program. Journal of Sports Medicine and Physical Fitness, 32: 347-352.

6. Clark CJ (1992). The role of physical training in asthma. Chest, 101: 293-298.

7. Strunk RC, Mrazek DA, Fukuhara JT et al. (1989). Cardiovascular fitness in children with asthma correlates with psychologic functioning of the child. Pediatrics, 84: 460-464.

8. Counil FP, Karila C, Varray A et al. (2001). Anaerobic fitness in children with asthma: adaptation to maximal intermittent short exercise. Pediatric Pulmonology, 31: 198-204.

9. Satta A (2000). Exercise training in asthma. Journal of Sports Medicine and Physical Fitness, 40: 277-283.

10. Ram FS, Robinson SM \& Black PN (2000). Effects of physical training in asthma: a systematic review. British Journal of Sports Medicine, 34: 162-167.

11. Martin RJ, Cicutto LC \& Smith HR (1991). Airways inflammation in nocturnal asthma. American Review of Respiratory Disease, 143: 351-357.

12. Vianna EO, Boaventura LC, Terra-Filho J et al. (2002). Morning-toevening variation in exercise-induced bronchospasm. Journal of Allergy and Clinical Immunology, 110: 236-240.

13. National Institutes of Health: National Heart, Lung and Blood Insti- tute (1997). Highlights of the expert panel report II: Guidelines for the diagnosis and management of asthma (GINA). American Academy of Asthma, Allergy and Immunology, 50.

14. American Thoracic Society (1995). Standardization of Spirometry. American Journal of Respiratory and Critical Care Medicine, 152 1107-1136.

15. Winsley RJ, Armstrong N, Bywater K et al. (2003). Reliability of heart rate variability measures at rest and during light exercise in children. British Journal of Sports Medicine, 37: 550-552.

16. Rowlands AV, Eston RG \& Ingledew DK (1997). Measurement of physical activity in children with particular reference to the use of heart rate and pedometry. Sports Medicine, 24: 258-272.

17. Landstra AM, Postma DS, Boezen HM et al. (2002). Role of serum cortisol levels in children with asthma. American Journal of Respiratory and Critical Care Medicine, 165: 708-712.

18. Strunk RC, Rubin D, Kelly L et al. (1988). Determination of fitness in children with asthma. Use of standardized tests for functional endurance, body fat composition, flexibility and abdominal strength. American Journal of Diseases of Children, 142: 940-944.

19. Jackson AS \& Coleman AE (1976). Validation of distance run tests for elementary school children. Research Quarterly, 47: 86-94.

20. Anonymous (1985). Summary of findings from National Children and Youth Fitness Study (1985). Journal of Physical Education, Recreation, and Dance, 56: 43-90.

21. Hallstrand TS, Bates PW \& Schoene RB (2000). Aerobic conditioning in mild asthma decreases the hyperpnea of exercise and improves exercise and ventilatory capacity. Chest, 118: 1460-1469.

22. Nickerson BG, Bautista DB, Namey MA et al. (1983). Distance running improves fitness in asthmatic children without pulmonary complications or changes in exercise-induced bronchospasm. Pediatrics, 71: 147-152.

23. Cochrane LM \& Clark CJ (1990). Benefits and problems of a physical training programme for asthmatic patients. Thorax, 45: 345-351. 
24. Neder JA, Nery LE, Silva AC et al. (1999). Short-term effects of aerobic training in the clinical management of moderate to severe asthma in children. Thorax, 54: 202-206.

25. Giacomoni M, Bernard T, Gavarry O et al. (1999). Diurnal variations in ventilatory and cardiorespiratory responses to submaximal treadmill exercise in females. European Journal of Applied Physiology and Occupational Physiology, 80: 591-597.

26. Bernard T, Giacomoni M, Gavarry O et al. (1998). Time-of-day effects in maximal anaerobic leg exercise. European Journal of Applied Physiology and Occupational Physiology, 77: 133-138.

27. Aoki K, Kondo N, Shimomura Y et al. (2002). Time-of day effect on nonthermal control of sweating response to maintained static exercise humans. European Journal of Applied Physiology, 86: 388-393.

28. McConnell AK \& Romer LM (2004). Dyspnoea in health and obstructive pulmonary disease: the role of respiratory muscle function and training. Sports Medicine, 34: 117-132. 